\title{
Patient Safety - Protect Yourself from Medical Errors: Aniruddha Malpani (Ed)
}

\author{
Published by Dr. Aniruddha Malpani, HELP - Health Education Library for People; \\ Ashish, Tardeo, Mumbai; Website: www.safetyforpatients.in; Pages: 152; Price: Rs. 300
}

\author{
Ashok Kumar Dutta ${ }^{1}$
}

Received: 29 August 2016 / Accepted: 29 August 2016 / Published online: 20 September 2016

(C) Dr. K C Chaudhuri Foundation 2016

Patient safety is one of the most important aspects of health care deliveries at all levels e.g., primary, secondary and tertiary care. An adverse event in the health care delivery system is not uncommon. Although the exact figure is difficult to ascertain, probably one in ten hospital admissions will have such an event. Many of these are preventable or if remedial actions are taken immediately, can save the lives. Patient safety is one of the most important element of efficient and effective health care system where no harm should be caused to any patient. Every doctor/nurse may recall more than one instance of their experience of committing an error in their patient management.

The "Patient Safety - Protect Yourself from Medical Errors" is an excellent and thought provoking book edited by Dr. Aniruddha Malpani who is an eminent personality and has unique distinction of managing world's largest free patient education Library (HELP).

I am touched by the bold confession of the author on his first preventable error in patient management. The same system of non-supervised or ill-supervised management practices are not a rarity even in present day health care delivery system. The educational curriculum of medical and nursing students is devoid of this important subject and probably only a brief mention of the same is a part of undergraduate and postgraduate training program.

This book highlights important aspects of patient safety, quality of care, medication error etc. at length. The definitions of patient safety and medical errors, which are not necessarily be intentional and often may be a system error has been expressed in detail by the author. The important points to be taken care of by the medical doctors and nurses to prevent medical errors and safeguard oneself has been described in very simplified manner. The role of policy makers, equipments and pharmaceutical companies in patient safety has been nicely dealt in this book. All the thirty eight chapters in the book are key elements which every health care professional, administrator, policy maker and nurse must know and practice in day to day life.

The chapters are written in great style and language which is easy to read and understand.

The book shall be of immense benefit and help for all the health care workers and policy makers and should find a place in the desk top of every professional caring for their patients.
Ashok Kumar Dutta

drdutta@gmail.com; duttaakd47@yahoo.co.in

1 Department of Pediatrics, School of Medical Sciences and Research, Sharda University, Greater Noida, Uttar Pradesh 201014, India 